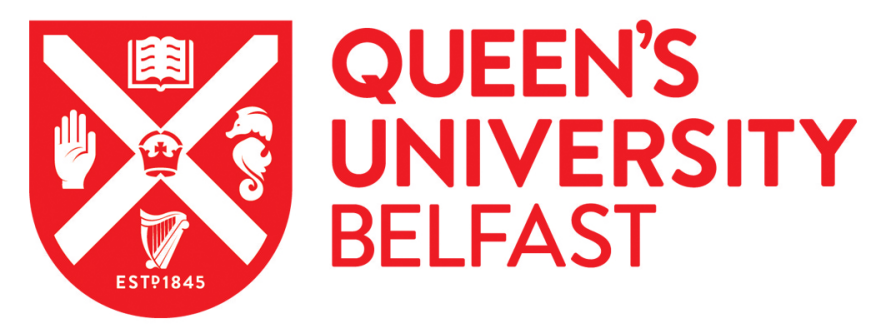

\title{
Loop-mediated isothermal amplification for the early diagnosis of invasive meningococcal disease in children
}

Paediatric Emergency Research in the UK and Ireland (PERUKI) (2020). Loop-mediated isothermal amplification for the early diagnosis of invasive meningococcal disease in children. Archives of Disease in Childhood, 105(12), 1151-1156. https://doi.org/10.1136/archdischild-2020-319139

Published in:

Archives of Disease in Childhood

Document Version:

Peer reviewed version

Queen's University Belfast - Research Portal:

Link to publication record in Queen's University Belfast Research Portal

Publisher rights

(C) 2020 BMJ Publishing Group Ltd \& Royal College of Paediatrics .

This work is made available online in accordance with the publisher's policies. Please refer to any applicable terms of use of the publisher.

\section{General rights}

Copyright for the publications made accessible via the Queen's University Belfast Research Portal is retained by the author(s) and / or other copyright owners and it is a condition of accessing these publications that users recognise and abide by the legal requirements associated with these rights.

Take down policy

The Research Portal is Queen's institutional repository that provides access to Queen's research output. Every effort has been made to ensure that content in the Research Portal does not infringe any person's rights, or applicable UK laws. If you discover content in the Research Portal that you believe breaches copyright or violates any law, please contact openaccess@qub.ac.uk. 


\section{Loop-mediated isothermal amplification (LAMP) for the early diagnosis of invasive meningococcal disease in children.}

\section{Author list \& institutions}

1. Thomas Waterfield (BMBCh)

a. Emergency Department, Royal Belfast Hospital for Sick Children, Belfast, UK

b. Centre for Experimental Medicine, Wellcome Wolfson Institute of Experimental Medicine, Queen's University Belfast, Belfast, UK

2. Mark D Lyttle (MBChB)

a. Emergency Department, Bristol Royal Hospital for Children, Bristol, UK

b. Faculty of Health and Applied Sciences, University of the West of England, Bristol, UK

3. James P McKenna (PhD)

a. Department of Microbiology, Belfast Health and Social Care Trust, Belfast, UK

4. Julie-Ann Maney (MBBCh)

a. Emergency Department, Royal Belfast Hospital for Sick Children, Belfast, UK

5. Damian Roland (PhD)

a. SAPPHIRE Group, Health Sciences, Leicester University, Leicester, UK

6. Michael Corr (MBBCh)

b. Children's Emergency Department, Leicester Royal Infirmary, Leicester, UK

a. Belfast Health and Social Care Trust, Belfast, UK

7. Kerry Woolfall (PhD)

a. Institute of Population Health and Society, The University of Liverpool, Liverpool, UK

8. Bethany Patenall (MSc)

a. Department of Chemistry, University of Bath, Bath, UK

9. Michael D Shields (PhD)

a. Centre for Experimental Medicine, Wellcome Wolfson Institute of Experimental Medicine, Queen's University Belfast, Belfast, UK

10. Derek Fairley $(\mathrm{PhD})$

a. Department of Microbiology, Belfast Health and Social Care Trust, Belfast, UK

b. Centre for Experimental Medicine, Wellcome Wolfson Institute of Experimental Medicine, Queen's University Belfast, Belfast, UK

Corresponding author - Thomas Waterfield, Centre for Experimental Medicine, Wellcome Wolfson Institute of Experimental Medicine, Queen's University Belfast, Belfast, UK

t.waterfield@qub.ac.uk

Phone: 07872990521

On behalf of Paediatric Emergency Research in the UK and Ireland (PERUKI) 


\section{Abstract \\ Background}

Rapid molecular diagnostic testing has the potential to improve the early recognition of meningococcal disease (MD). The aim of this study was to report on the diagnostic test accuracy of point-of-care loopmediated isothermal amplification (LAMP) in the diagnosis of MD.

\section{Design}

Data was collected prospectively from three UK emergency departments (ED) between November 2017 and June 2019. Consecutive children under 18 years of age attending the ED with features of MD were eligible for inclusion. The meningococcal LAMP test (index test) was performed on a dry swab of the child's oropharynx. Reference standard testing was the confirmation of invasive meningococcal disease defined as positive N. meningitidis culture or PCR result from a sterile body site (blood or CSF).

\section{Results}

There were 260 children included in the final analysis. The median age was two years 11 months and $169(65 \%)$ children were aged five years or younger. The LAMP test was negative in 246 children and positive in 14 children. Of the 14 children with positive LAMP tests there were five cases of invasive meningococcal disease. Of the 246 children with negative LAMP tests there were no cases of invasive meningococcal disease. The sensitivity of LAMP testing was 1.00 and the specificity was 0.97 . The Negative and Positive predictive values were 1.00 and 0.36 respectively. The positive likelihood ratio was 28.3.

\section{Discussion}

Non-invasive LAMP testing using oropharyngeal swabs provided an accurate fast and minimally invasive mechanism for predicting invasive meningococcal disease in this study.

\section{Registration}

Registered at https://www.clinicaltrials.gov (trial registration: NCT03378258) on the $19^{\text {th }}$ of December 2017. 


\section{Introduction}

Invasive meningococcal disease (MD) occurs when Neisseria meningitidis ( $N$. meningitidis) crosses from the respiratory mucosa and invades the host (1). N. meningitidis is a gram-negative diplococcus that colonises the nasopharynx and oropharynx of humans $(1,2)$. In most people carriage is asymptomatic but in a minority the bacteria cross the mucosa and enter the blood (1). Once $N$. meningitidis crosses from the naso/oropharynx to the blood it can multiply rapidly with resultant bacteraemia and an associated cytokine storm (1). This leads to increased host vascular permeability, organ dysfunction, and disseminated intravascular coagulation (1). N. meningitidis may also cross the blood-brain barrier resulting in meningitis. Even in resource rich settings invasive meningococcal disease carries an approximate $5-10 \%$ risk of mortality (1-5).

The early recognition of MD is challenging in children because during the prodrome phase MD often presents with symptoms and signs that are indistinguishable from self-limiting infections (5-7). When there is diagnostic uncertainty clinicians may perform tests such as a full blood count (FBC), C-reactive protein (CRP) and Procalcitonin (PCT) to identify those at highest risk $(5,7)$, but these conventional tests lack the necessary sensitivity to rule out MD (5). This leads to many children receiving unnecessary parenteral antibiotics (just in case) whilst others are incorrectly reassured and discharged home $(5,7)$.

Recent advances in molecular diagnostics have resulted in the development of Loop-mediated isothermal amplification (LAMP) technology $(8,9)$. LAMP is a form of rapid nucleic acid amplification that utilises specific looped primers and strand displacing DNA polymerase (9). LAMP has several advantages over traditional molecular diagnostic techniques such as polymerase chain reaction (PCR) including rapidity, amount of equipment required, and tolerance of biological fluids (which facilitates direct testing of clinical material).

A commercially available CE-marked LAMP test has been developed for the rapid detection of the ctrA gene present within all serogroups of $N$. meningitides, and can be performed on a range of specimen types including blood, cerebrospinal fluid (CSF) and naso/oropharyngeal swabs (8,9). Data collected 
during the development of this LAMP test suggested it has the potential to outperform traditional testing for MD identification in children (8,9), and its performance accuracy is equivalent on naso/oropharyngeal samples and blood testing (10). Naso/oropharyngeal swabs are easy to collect and require minimal DNA extraction (heating for five minutes) as opposed to blood which requires phlebotomy and a more complicated DNA extraction process $(8,9)$. However nasal carriage of meningococci, rates of which vary across populations and age, may result in a positive test and unnecessary treatment $(8,10-12)$. Such carriage is uncommon in infancy and early-childhood $(<5 \%)$, but increases steadily to a peak in adolescence (approximately 25\%) (11-14).

The primary objective of this study was to evaluate the diagnostic accuracy of LAMP testing of oropharyngeal swabs for identifying invasive MD in children and to compare LAMP testing with conventional tests such as CRP and white cell counts.

\section{Methods}

The data for this diagnostic accuracy study come from the Petechiae in Children (PiC) study (15), a mixed method prospective, multicentre cohort study. The full protocol is available as an open access publication (15). The PiC study was designed and reported in line with the Standards for Reporting Diagnostic accuracy studies (STARD) statement (16).

\section{Participants}

Consecutive children under 18 years of age attending Emergency Departments (ED) with a reported or recorded fever $\left(\geq 38^{\circ} \mathrm{C}\right)$ and features of meningococcal sepsis/meningitis were eligible for inclusion. The case report form (Supplementary material) included 29 possible features of meningococcal sepsis/meningitis based on NICE guidance and based on a published review conducted by the research team $(1,5)$. Children with pre-existing conditions predisposing to non-blanching rash including haematological malignancy, idiopathic thrombocytopenic purpura (ITP), coagulopathy, and active Henoch-Schonlein purpura (HSP) were excluded. Participants for this analysis were enrolled between the $9^{\text {th }}$ of November 2017 and the $30^{\text {th }}$ of June 2019 at three EDs in the UK. 


\section{Test methods}

The index test employed in the study was the commercially available HG Direct Swab meningococcus LAMP test "HG-MENDS" (HiberGene Diagnostics Ltd, Ireland). This assay consists of reaction strips containing lyophilised reaction mix comprised of specific primers targeting a conserved region of the $N$. meningitidis ctrA gene, an exogenous bacteriophage sequence used as assay extraction control together with strand displacing polymerase enzyme, an intercalating dye and all other necessary reagents and buffer. Testing was performed on dry Nylon FLOQSwabs ${ }^{\circledR}$ product code 519C (Copan diagnostics, Italy) of the child's oropharynx. Swabs were collected by ED clinical staff during the initial assessment of the child and placed in supplied HG elution buffer (HiberGene Diagnostics Ltd, Ireland) denatured at $95^{\circ} \mathrm{C}$ for 5 minutes with a $50 \mu \mathrm{l}$ aliquot analysed immediately as per the manufacturer's instructions for use (http://www.hibergene.com/products/hg-meningococcus/). All reactions were performed in the ED using a supplied HG Swift LAMP instrument (HiberGene Diagnostics Ltd, Ireland) which interprets generated fluorescent signals in real time. The total run time for each sample was 40 minutes. At the end of each run HG swift reported one of three results - positive, negative or invalid.

The reference standard for invasive MD was positive culture or PCR for N. meningitidis from a sterile body site (blood or CSF). Reference standard testing was performed at accredited NHS hospital laboratories by individuals blinded to the results of the index test. In all instances LAMP testing was performed prior to the results of the reference standard testing being available.

\section{Follow up}

Researchers at each site checked attendance records at seven days to monitor for any unplanned reattendances by study participants. Participating institutions also cross-referenced enrolled children with notifications of MD from their hospital laboratory to Public Health England or the Public Health Agency Northern Ireland. These processes ensured that all cases of MD were recorded, including any who had been discharged without treatment. In situations where the child was enrolled but discharged home without reference standard testing, they were assumed to not have MD provided they met the following criteria:

1) They were not subsequently diagnosed with MD within seven days of discharge 
2) They did not have a MD notification to public health

\section{Analysis}

The study population was described in terms of demographic characteristics with median age and gender. Simple descriptive statistics (total number and proportion) were used to describe vaccination status, parenteral antibiotic use, admission to hospital, admission to intensive care units, and survival. The diagnostic accuracy of LAMP testing was reported as sensitivity, specificity, negative predictive value (NPV), positive predictive value (PPV) and negative/positive likelihood ratios (LHR) with 95\% confidence intervals $(\mathrm{Cl})$. In situations where the LAMP test provided an invalid result the test result was excluded from analysis.

\section{Sample size calculation}

As per the published protocol we calculated that we would need 203 LAMP negative patients to estimate an NPV of $95 \%$ or greater with Cls of $+/-3 \%$. Disease prevalence was estimated at $15 \%$ or lower, based on preparatory work in our centre and other epidemiologic studies, and we anticipated a combined refusal of consent and dropout rate of $10 \%$. Accounting for these factors we calculated that we would need to recruit 250 participants.

\section{Consent Model}

Due to the potentially life-threatening nature of MD we used research without prior consent (RWPC) (17), described in detail elsewhere $(15,18)$. All participants were invited to provide consent at the earliest appropriate opportunity once the clinical condition had stabilised (typically within 24 hours of enrolment).

\section{Data Management}

Study data were collected and managed using REDCap (Research Electronic Data Capture). The initial REDCap case report form (CRF1) was used to contemporaneously record data regarding the initial clinical assessment and results of LAMP testing. The second CRF was completed seven days after discharge and was used to record laboratory results, length of stay, and other aspects of care not susceptible to recall bias (Copies of the CRFs are available in supplementary material). 
Public and patient involvement (PPI)

There has been public and patient involvement with the PiC study from outset. The PPI group assisted in the design of the PiC study including the protocol, study information, and RWPC methodology. The lead of the PPI group sat on the trial oversight committee and received regular updates regarding progress, and was a co-author of the published PiC protocol (15). PPI group members have promoted the study locally and nationally through appearances on local and national radio and television.

Office for Research Ethics Committees (OREC) and local Research Governance

The study was approved by both the Northern Ireland OREC (Project ID 224660, OREC ID 17/NI/0169) and by the Belfast Health and Social Care Trust Research Governance.

\section{Study Registration}

The PiC study was registered at https://www.clinicaltrials.gov (trial registration: NCT03378258) on the $19^{\text {th }}$ of December 2017.

\section{Findings}

A total of 304 consecutive children were screened for inclusion in the study across the three sites, of which 24 were ineligible; 18 of these were screened after hospital admission and laboratory testing, four did not meet inclusion criteria, two could not provide consent due to unavailability of translators, and one declined consent. Of the 280 participants, 17 did not have LAMP testing performed due to a lack of time and/or trained staff, and three had invalid results, leaving 260 patients for inclusion in the final analysis. The three invalid results occurred in children without MD (Figure 1). Of the analysis population of 260, 245 were enrolled in the lead study site, 12 from the second site, and three from the third site. Reference standard testing was performed in 253 participants; none of the seven children without reference standard testing received parenteral antibiotics, all were diagnosed with "viral illness" by the discharging clinician, and none re-presented within seven days of discharge.

142 participants (54.6\%) were male, and the median age was two years, 11 months (range 1 month 13 years, 11 months), with $169(65 \%)$ aged five years or younger. A total of $253(97.3 \%)$ were 
appropriately vaccinated for age according to the UK vaccination schedule; $150(57.7 \%)$ had received meningococcal B vaccination, and $179(68.8 \%)$ meningococcal C vaccination. Parenteral antibiotics were given to $120(46.2 \%)$, and $142(54.6 \%)$ were admitted; four were admitted to a paediatric intensive care unit (PICU) and one died. There were five (1.9\%) confirmed cases of invasive MD (Tables 1 and 2), all of which had positive blood PCR for $N$. meningitidis. One case was confirmed by both culture and PCR for N. meningitidis in blood (Table2).

The LAMP testing of oropharyngeal swabs was positive in 14 children, of whom five had invasive MD (Table 2). All five cases of invasive MD were recruited from the Royal Belfast Hospital for Sick Children. Of the 246 with negative LAMP tests there were no cases of invasive MD. The sensitivity of LAMP testing was $1.00(95 \% \mathrm{Cl} 0.46-1.00)$ and the specificity was 0.97 (95\% $\mathrm{Cl} 0.93-0.98)$. The NPV and PPV were $1.00(95 \% \mathrm{Cl} 0.98-1.00)$ and $0.36(95 \% \mathrm{Cl} 0.14-0.64)$ respectively. The positive likelihood ratio was 28.3 (95\% Cl 14.9-53.8); the negative likelihood ratio was incalculable due to there being no false negatives in this cohort (Table 3). In all instances the LAMP test result was available within 40 minutes. The oropharyngeal swabs used to perform LAMP testing underwent additional laboratory testing for meningococcal ctrA gene using PCR. Of the 260 analysed oropharyngeal specimens, seven (2.7\%) tested positive for $N$. meningitidis and 253 tested negative. The seven positive test results included all of the cases of invasive MD.

All of the 260 children included in the final analysis had data relating to their measured C-reactive protein levels (CRP), total white cell counts (WCC) and neutrophil counts recorded. The diagnostic accuracy of these tests are shown in Table 4. The LAMP test performed better than CRP, WCC or neutrophil counts in this population with a significantly higher specificity $(p<0.0001)$ for all.

\section{Interpretation}

This study found the LAMP test can be performed using oropharyngeal swabs in the ED, as a point-ofcare test, with results available within the hour. The invalid rate was low $(n=3 ; 1.1 \%)$ and the LAMP test was highly sensitive and specific for identification of invasive MD. The LAMP test performed favourably when compared to conventional tests such as CRP, WCC and neutrophil count in this cohort. 
Although vaccination programmes have made MD uncommon in the UK, a small but significant number of children develop invasive MD each year $(19,20)$. Differentiating children with MD from those with a self-limiting viral infection is increasingly difficult on clinical grounds alone. Existing biomarkers such as CRP, WCC, and neutrophil counts, are of little additional help to clinicians given their inaccuracy for predicting MD $(5,21)$. The findings of the parent study from which the data in this analysis are drawn (the PiC study) further support this, demonstrating that an abnormal WCC, neutrophil count or elevated CRP were all poorly specific for MD $(0.67,029$ and 0.73$)$ respectively (22). These specificities were significantly lower than that of the LAMP test (specificity $0.97, p<0.0001$ ).

In summary the LAMP test was as sensitive as CRP at a cut-off of $6 \mathrm{mg} / \mathrm{l}$ and more specific than an abnormal WCC or an elevated neutrophil count for the detection of MD. The LAMP test conferred additional benefits for patients, including a quicker time to result than conventional microbiology testing and it would be entirely plausible for a child to have their throat swabbed at triage and results available within the hour.

Further research to fully ascertain the best use of LAMP testing within the diagnostic pathway is required but potential uses include as an adjuvant to blood culture and PCR techniques to rapidly identify those children with likely MD and tailor antimicrobial therapy.

\section{Limitations}

This study has some limitations. Firstly, the majority of participants were under five years of age, a group which has low carriage rates of $N$. meningitidis in the naso/oropharynx. This will have overinflated the specificity of the LAMP test due to fewer false positive results than would be seen with higher carriage rates. Our findings should therefore be applied with caution to populations with higher carriage rates, such as adolescents and young adults, and its performance accuracy is worthy of further study in this age group.

There were seven recorded false positive results (positive on LAMP testing but negative by PCR using the same swab) it is unclear if the difference in results was due to issues with handling samples (i.e. genuine false positives) within the ED or due to a greater sensitivity of LAMP testing compared to 
conventional PCR. Previous studies have suggested that molecular amplification techniques utilising LAMP technology may offer a greater sensitivity than conventional PCR techniques (10). Further research to determine if LAMP testing in the ED results in a greater number of false positives than LAMP testing in a laboratory setting could help to determine the ideal location and service model for LAMP testing. One potential solution could be co-located laboratories within the ED able to perform rapid tests including some molecular diagnostic tests.

The presented data is based on very few cases $(N=5)$ of confirmed invasive MD, resulting in wide $95 \%$ confidence intervals for sensitivity. This was despite the selection of eligibility criteria designed to include only participants with symptoms or signs suggestive of MD. Further study in a high prevalence setting would therefore be helpful to further illuminate the performance accuracy of LAMP as a rule out test in isolation. Based on this study alone, with only five cases of MD, the LAMP test could not be used as a rule out-test.

Finally the majority of the LAMP testing occurred in a single large tertiary children's hospital. While it is likely that this centre is similar to other large city secondary and tertiary care centres, the dominance of one centre increases the inherent risk of bias within the study and makes the results more difficult to generalise. A prospective multicentre study involving a range of site types, and a greater number of older children and adolescents, is required to fully understand the clinical utility of the LAMP test.

\section{What is known about this topic?}

Invasive meningococcal disease occurs when Neisseria meningitidis crosses from the respiratory mucosa and invades the host. Even in resource rich settings invasive meningococcal disease carries an approximate $5-10 \%$ risk of mortality.

Recent advances in molecular diagnostics have resulted in the development of Loop-mediated isothermal amplification (LAMP) technology. LAMP is a form of rapid nucleic acid amplification that has several advantages over traditional molecular diagnostic techniques such as polymerase chain reaction 
(PCR) including rapidity, amount of equipment required, and tolerance of biological fluids (which facilitates direct testing of clinical material).

\section{What this study adds}

A meningococcus LAMP test can be performed using oropharyngeal swabs with results available within one hour. The test was highly sensitive and specific for identification of invasive meningococcal disease. The LAMP test performed favourably when compared to conventional tests such as CRP, WCC and neutrophil count.

\section{Declarations}

- Ethics approval The Northern Ireland Research Ethics Committee (REC Reference 17/NI/0169) and the Belfast Health \& Social Care Trust Research Governance (Reference $16201 \mathrm{MS}-\mathrm{SW}$ ) approved the protocol.

- Declaration of interests: Dr McKenna Holds share options in HiberGene Diagnostics Ltd.

- Funding This study was primarily funded by the Public Health Agency of Northern Ireland (EAT/5313/16). The Royal College of Emergency Medicine provided some additional funding. The funder had no involvement in the design or conduct of the study.

- $\quad$ Authors contributions Dr Waterfield, Dr Lyttle, Dr Roland, Dr Maney, Dr Fairley, Dr Mckenna and Professor Shields conceived and designed the study. Dr Waterfield co-ordinated the running of the study including data management and site training. Dr Corr and Ms Patenall were involved with the conduct of the study including data collection. Dr Woolfall provided study design expertise and designed the approach to consent.

- Acknowledgements We would like to thank all of the children and their families who participated in this study. We would also like to thank all of the people involved with screening and recruiting patients to the $\mathrm{PiC}$ study.

- Data Sharing All of the individual participant data collected during this study will be available (including data dictionaries) on the Queen's University Belfast data repository. The full study protocol is available as an open access publication. 


\section{References}

1. Corr M, Waterfield T, Shields M. Fifteen-minute consultation: Symptoms and signs of meningococcal disease. Arch Dis Child - Educ Pract [Internet]. 2019 Oct 16 [cited 2019 Oct 17];edpract-2019-317722. Available from: https://ep.bmj.com/content/early/2019/10/16/archdischild-2019-317722

2. Sabra A, Benger J. Meningococcal disease in children: a clinical review. Turk J Pediatr [Internet]. [cited 2019 Nov 14];53(5):477-88. Available from: http://www.ncbi.nlm.nih.gov/pubmed/22272447

3. Mandl KD, Stack AM, Fleisher GR. Incidence of bacteremia in infants and children with fever and petechiae. J Pediatr [Internet]. 1997;131(3):398-404. Available from: http://ovidsp.ovid.com/ovidweb.cgi?T=JS\&PAGE=reference\&D=med4\&NEWS=N\&AN=932941 6

4. Wells LC, Smith JC, et al. The child with a non-blanching rash: How likely is meningococcal disease? Arch Dis Child [Internet]. 2001;85(3):218-22. Available from: http://ovidsp.ovid.com/ovidweb.cgi?T=JS\&PAGE=reference\&D=med4\&NEWS=N\&AN=115171 04

5. NICE. Meningitis (bacterial) and meningococcal septicaemia in under 16s: recognition, diagnosis and management | Guidance and guidelines | NICE. 2015 [cited 2017 Oct 10]; Available from: https://www.nice.org.uk/guidance/cg102

6. Ó Maoldomhnaigh C, Drew RJ, Gavin P, Cafferkey M, Butler KM. Invasive meningococcal disease in children in Ireland, 2001-2011. Arch Dis Child [Internet]. 2016 Dec [cited 2017 Oct 10];101(12):1125-9. Available from: http://www.ncbi.nlm.nih.gov/pubmed/27566800

7. Riordan FAl, Jones L, Clark J. Validation of two algorithms for managing children with a nonblanching rash. Arch Dis Child. 2016;709-13.

8. Bourke TWTW, McKenna JPJP, et al. Diagnostic accuracy of loop-mediated isothermal amplification as a near-patient test for meningococcal disease in children: An observational cohort study. Lancet Infect Dis [Internet]. 2015;15(5):552-8. Available from:

http://ovidsp.ovid.com/ovidweb.cgi?T=JS\&PAGE=reference\&D=med8\&NEWS=N\&AN=257288 43

9. McKenna JPJP, Fairley DJDJ, Shields MDMD, Cosby SLSL, Wyatt DEDE, McCaughey C, et al. Development and clinical validation of a loop-mediated isothermal amplification method for the rapid detection of Neisseria meningitidis. Diagn Microbiol Infect Dis [Internet]. 2011 [cited 2017 Sep 12];69(2):137-44. Available from:

http://ovidsp.ovid.com/ovidweb.cgi?T=JS\&PAGE=reference\&D=emed13\&NEWS=N\&AN=3611 14317

10. Waterfield T, Fairley D, Blackwood B, McKenna J, Shields MD. A systematic review of the diagnostic accuracy of Loop-mediated-isothermal AMPlification (LAMP) in the diagnosis of invasive meningococcal disease in children. BMC Pediatr [Internet]. 2019 Dec 7 [cited 2019 Dec 3];19(1):49. Available from:

https://bmcpediatr.biomedcentral.com/articles/10.1186/s12887-019-1403-0

11. Caugant DA, Maiden MCJ. Meningococcal carriage and disease-Population biology and evolution. Vaccine [Internet]. 2009;27(SUPPL. 2):B64-70. Available from: http://dx.doi.org/10.1016/j.vaccine.2009.04.061

12. Christensen H, May M, Bowen L, Hickman M, Trotter CL. Meningococcal carriage by age: a systematic review and meta-analysis. Lancet Infect Dis [Internet]. 2010 Dec [cited 2018 Jan 8];10(12):853-61. Available from: http://www.ncbi.nlm.nih.gov/pubmed/21075057

13. Ala'Aldeen D, Oldfield NJ, Bidmos FA, Abouseada NM, Ahmed NW, Turner DPJ, et al. Carriage of Meningococci by University Students, United Kingdom. Emerg Infect Dis [Internet]. 2011 Sep [cited 2018 Jan 8];17(9):1762-3. Available from: http://www.ncbi.nlm.nih.gov/pubmed/21888817

14. MacLennan J, Kafatos G, Neal K, Andrews N, Cameron JC, Roberts R, et al. Social behavior and meningococcal carriage in British teenagers. Emerg Infect Dis [Internet]. 2006 Jun [cited 2018 Jan 8];12(6):950-7. Available from: http://www.ncbi.nlm.nih.gov/pubmed/16707051

15. Waterfield T, Lyttle MD, Fairley D, Mckenna J, Woolfall K, Lynn F, et al. The "Petechiae in children" (PiC) study: evaluating potential clinical decision rules for the management of feverish children with non-blanching rashes, including the role of point of care testing for Procalcitonin \&amp; Neisseria meningitidis DNA - a study protocol. BMC Pediatr [Internet]. 2018 Dec 30 [cited 2018 Sep 25];18(1):246. Available from:

http://www.ncbi.nlm.nih.gov/pubmed/30060751 
16. Bossuyt PM, Reitsma JB, Bruns DE, Gatsonis CA, Glasziou PP, Irwig L, et al. STARD 2015: an updated list of essential items for reporting diagnostic accuracy studies. BMJ [Internet]. 2015 Oct 28 [cited 2018 Sep 25];h5527. Available from: http://www.bmj.com/lookup/doi/10.1136/bmj.h5527

17. CONNECT advisory group. Research without prior consent (deferred consent) in trials investigating the emergency treatment of critically ill children: CONNECT study guidance Version 2 updated July 2015 http://www.liv.ac.uk/psychology-health-andsociety/research/connect/. 2015;(July).

18. Waterfield T, Lyttle MD, Shields M, Fairley D, Roland D, McKenna J, et al. Parents' and clinicians' views on conducting paediatric diagnostic test accuracy studies without prior informed consent: qualitative insight from the Petechiae in Children study (PiC). Arch Dis Child [Internet]. 2019 Oct 1 [cited 2019 Oct 17];104(10):979-83. Available from:

http://www.ncbi.nlm.nih.gov/pubmed/31175126

19. Ladhani SN, Andrews N, Parikh SR, Campbell H, White J, Edelstein M, et al. Vaccination of Infants with Meningococcal Group B Vaccine (4CMenB) in England. N Engl J Med [Internet]. 2020 Jan 23 [cited 2020 Jan 29];382(4):309-17. Available from:

http://www.nejm.org/doi/10.1056/NEJMoa1901229

20. Halperin SA, Bettinger JA, Greenwood B, Harrison LH, Jelfs J, Ladhani SN, et al. The changing and dynamic epidemiology of meningococcal disease. Vaccine [Internet]. 2012;30(SUPPL. 2):B26-36. Available from: http://dx.doi.org/10.1016/j.vaccine.2011.12.032

21. Bell JM, Shields MD, Agus A, Dunlop K, Bourke T, Kee F, et al. Clinical and CostEffectiveness of Procalcitonin Test for Prodromal Meningococcal Disease-A Meta-Analysis. 2015 [cited 2019 Dec 10]; Available from: https://www.ncbi.nlm.nih.gov/pmc/articles/PMC4459795/pdf/pone.0128993.pdf

22. Waterfield $T$ et al. Validating clinical practice guidelines for the management of children with non-blanching rashes in the United Kingdom. [ACCEPTED FOR PUBLICATION] 
Figure 1: Flow of patients through the study

Table 1: Summary for the 260 study participants seen in Emergency Departments with suspected Meningococcal disease ( $\mathrm{n}$ and $(\%)$ unless otherwise stated)

\begin{tabular}{|c|c|}
\hline Characteristic & \\
\hline Age (months; median (range)) & $35(1-156)$ \\
\hline Male sex & $142(54.6)$ \\
\hline Vaccination status & \\
\hline Vaccinations up-to-date & 253(97.3) \\
\hline Meningococcal B vaccinated & $150(57.7)$ \\
\hline Meningococcal C vaccinated & 179(68.8) \\
\hline Index Tests & \\
\hline LAMP & $260(100)$ \\
\hline C-reactive protein & $260(100)$ \\
\hline White cell counts & $260(100)$ \\
\hline Reference Standard & \\
\hline Culture/PCR & 253(97.3) \\
\hline Presumed negative & $7(2.7)$ \\
\hline Outcomes & \\
\hline $\begin{array}{l}\text { Received parenteral antibiotics at first } \\
\text { presentation }\end{array}$ & $120(46.2)$ \\
\hline Admitted to hospital & 142(54.6) \\
\hline Admitted to PICU & 4(1.5) \\
\hline Deaths & $1(0.4)$ \\
\hline Confirmed meningococcal disease & $5(1.9)$ \\
\hline
\end{tabular}


Table 2: Summary of children with confirmed meningococcal disease

\begin{tabular}{|c|c|c|c|c|c|c|c|}
\hline DIAGNOSIS & BLOOD CULTURE & BLOOD PCR & AGE & $\begin{array}{l}\text { RECEIVED } \\
\text { MENINGOCOCCAL B } \\
\text { VACCINE }\end{array}$ & $\begin{array}{l}\text { RECEIVED } \\
\text { MENINGOCOCCAL } \\
\text { C VACCINE }\end{array}$ & $\begin{array}{l}\text { ADMITTED } \\
\text { TO } \\
\text { INTENSIVE } \\
\text { CARE }\end{array}$ & SURVIVAL \\
\hline N. MENINGITIDIS B & Negative & N. meningitidis $B$ & 4 years 10 months & No & Yes & Yes & Yes \\
\hline N. MENINGITIDIS B & Negative & N. meningitidis $B$ & 4 years 10 months & No & Yes & Yes & Yes \\
\hline N. MENINGITIDIS B & Negative & N. meningitidis $B$ & 4 years 7 months & Yes & Yes & No & Yes \\
\hline N. MENINGITIDIS B & N. meningitidis $B$ & N. meningitidis $B$ & 3 months & Yes & No & Yes & No \\
\hline N. MENINGITIDIS B & Negative & N. meningitidis $B$ & 3 years 1 month & Yes & Yes & No & Yes \\
\hline
\end{tabular}


Table 3: Diagnostic accuracy of LAMP testing on oropharyngeal swabs for predicting meningococcal disease.

\begin{tabular}{|c|c|c|c|c|c|c|c|c|}
\hline \multirow{2}{*}{ Index Test } & \multicolumn{2}{|c|}{$\begin{array}{l}\text { Meningococcal } \\
\text { Disease }\end{array}$} & \multirow{2}{*}{$\begin{array}{l}\text { Sensitivity } \\
(95 \% \mathrm{Cl})\end{array}$} & \multirow{2}{*}{$\begin{array}{l}\text { Specificity } \\
(95 \% \mathrm{Cl})\end{array}$} & \multirow{2}{*}{$\begin{array}{c}\text { Positive } \\
\text { Predictive } \\
\text { Value }(95 \% \mathrm{Cl})\end{array}$} & \multirow{2}{*}{$\begin{array}{c}\text { Negative } \\
\text { Predictive } \\
\text { Value }(95 \% \mathrm{CI})\end{array}$} & \multirow{2}{*}{$\begin{array}{c}\text { Positive } \\
\text { Likelihood } \\
\text { Ration }(95 \% \mathrm{Cl})\end{array}$} & \multirow{2}{*}{$\begin{array}{c}\text { Negative } \\
\text { Likelihood } \\
\text { Ration }(95 \% \mathrm{Cl})\end{array}$} \\
\hline & Present & Absent & & & & & & \\
\hline LAMP Positive & 5 & 9 & \multirow{2}{*}{$1.00(0.46$ to 1.00$)$} & \multirow{2}{*}{$0.97(0.93$ to 0.98$)$} & \multirow{2}{*}{$0.36(0.14$ to 0.64$)$} & \multirow{2}{*}{$1.00(0.98$ to 1.00$)$} & \multirow{2}{*}{$28.3(14.9$ to 53.8$)$} & \multirow{2}{*}{ N/A } \\
\hline LAMP Negative & 0 & 246 & & & & & & \\
\hline
\end{tabular}


Table 4: Diagnostic accuracy of CRP, abnormal white cell count $(<5,000 / \mathrm{ul}$ or $>15,000 / \mathrm{ul})$ and elevated neutrophil count (>10,000/ul) at predicting meningococcal disease.

\begin{tabular}{|ccccccc|}
\hline Test & Sensitivity (95\% Cl) & Specificity (95\% Cl) & PPV (95\% Cl) & NPV (95\% Cl) & Positive LHR (95\% Cl) & Negative LHR (95\% Cl) \\
\hline C-reactive protein $>6 \mathrm{mg} / \mathrm{I}$ & $1.00(0.46$ to 1.0$)$ & $0.29(0.23$ to 0.35$)$ & $0.03(0.01$ to 0.06$)$ & $1.00(0.94$ to 1.00$)$ & $1.4(1.3$ to 1.5$)$ & NA \\
\hline C-reactive protein $\geq 10 \mathrm{mg} / \mathrm{I}$ & $1.00(0.46$ to 1.0$)$ & $0.39(0.33$ to 0.45$)$ & $0.03(0.01$ to 0.07$)$ & $1.00(0.95$ to 1.00$)$ & $1.6(1.5$ to 1.8$)$ & NA \\
\hline C-reactive protein $\geq 20 \mathrm{mg} / \mathrm{I}$ & $1.00(0.46$ to 1.0$)$ & $0.54(0.47$ to 0.60$)$ & $0.04(0.01$ to 0.10$)$ & $1.00(0.96$ to 1.00$)$ & $2.2(1.9$ to 2.5$)$ & NA \\
\hline C-reactive protein $\geq 50 \mathrm{mg} / \mathrm{I}$ & $0.60(0.17$ to 0.93$)$ & $0.78(0.73$ to 0.83$)$ & $0.05(0.01$ to 0.15$)$ & $0.99(0.96$ to 0.99$)$ & $2.8(1.3$ to 6.0$)$ & $0.5(0.2$ to 1.5$)$ \\
\hline Abnormal white cell count & $0.60(0.17$ to 0.93$)$ & $0.67(0.61$ to 0.73$)$ & $0.03(0.01$ to 0.11$)$ & $0.99(0.95$ to 1.00$)$ & $1.8(0.9$ to 3.9$)$ & $0.6(0.2$ to 1.7$)$ \\
\hline Elevated neutrophil count & $0.40(0.07$ to 0.83$)$ & $0.73(0.67$ to 0.78$)$ & $0.03(0.00$ to 0.11$)$ & $0.98(0.95$ to 1.00$)$ & $1.5(0.5$ to 4.4$)$ & $0.8(0.4$ to 1.7$)$ \\
\hline
\end{tabular}

